\title{
Investigation of Load Bearing Capacities of Grouted Rock Bolts with New Auxetic Head Designs
}

\author{
Eren Komurlu1 ${ }^{1 *}$, Aysegul Durmus Demir², Atila Gurhan Celik ${ }^{1}$ \\ 1 Department of Civil Engineering, Faculty of Engineering, Giresun University, 28200, Giresun, Turkey \\ 2 Department of Civil Engineering, Faculty of Engineering, Karadeniz Technical University, 61080, Trabzon, Turkey \\ * Corresponding author, e-mail: ekomurlu@giresun.edu.tr
}

Received: 30 April 2020, Accepted: 08 May 2020, Published online: 03 June 2020

\begin{abstract}
Within this study, new bolt heads were designed to be able to expand in drill holes as the load applied on the bolt shank increases. The heads of newly designed rock bolts include a conic part and split rings encircling them. To determine load bearing capacities of new rock bolts with varying angles of the conic parts and expansion properties, a series of deformation controlled pull-out tests were carried out by using bolt samples grouted in rock blocks. In addition to the experimental studies, numerical modelling analyses were performed to better understand the support properties of newly designed rock bolts. Because of a negative Poisson's ratio effect supplied by the head part expansion with the tension of the shank, new bolt heads are suggested to be defined as auxetic. According to the results of this study, the new head designs significantly improve the load bearing and energy absorption capacities of grouted rock bolts.
\end{abstract}

Keywords

grouted rock bolts, auxetic heads, anchorage mechanisms, support reactions of rock bolts

\section{Introduction}

Rock bolts, one of the main reinforcements used in the rock engineering have become worldwide popular since its invention in the early 20 th century [1-3]. The use of rock bolts have made a revolution of rock support in the second half of the 20th century. For instance, one of the main reasons for discovery and development of contemporary support strategies, which have supplied significant advances like invention of the New Austrian Tunnelling Method (NATM) was initiation of the use of rock bolts in rock engineering [4-6].

The rock bolts can be grouped in accordance with various parameters such as grout usage (grouted or friction bolts), grout material type (cement, resin, etc.), shank body material (steel, polymeric composites, etc.), pre-tensioning properties (active, passive), energy absorption capacities (energy-absorbing bolts and others) and etc. [7-9].

In this study, a new grouted rock bolt design was investigated with load bearing capacity tests. As the shank is tensioned, head parts of the newly designed bolts expand to supply better anchorages with increasing load level. Therefore, the head part of the new rock bolts can be classified as an auxetic structure which has negative Poisson's ratio effect by expanding in perpendicular to the tension direction of the bolt shanks. As a result of better anchorage by the expansion in the drill hole, the new bolts were designed to supply an improved support performance under increasing load condition. In other words, the new bolts are aimed to supply better resistivity against displacement of the shank in the hole as the load level increases. To make the auxetic reaction, bolts were produced with conic heads fixed to the shanks by welding and double semi-rings to encircle the head. To supply a proper contact with the cones, the inner sides of rings had same cut angles with those of the conic parts (Figs. 1 and 2). The semi-ring pieces are pushed towards to the drill hole surface, as a result of displacement of the cone part by the tension of the bolt shank. In addition to the expansion, the new design can supply ploughing in the hole, which make the energy absorption capacity better [10, 11]. Increasing energy absorption capacity is advantageous in terms of combating problematic rock masses such as those with burst, squeezing, swelling cases [12-14]. 


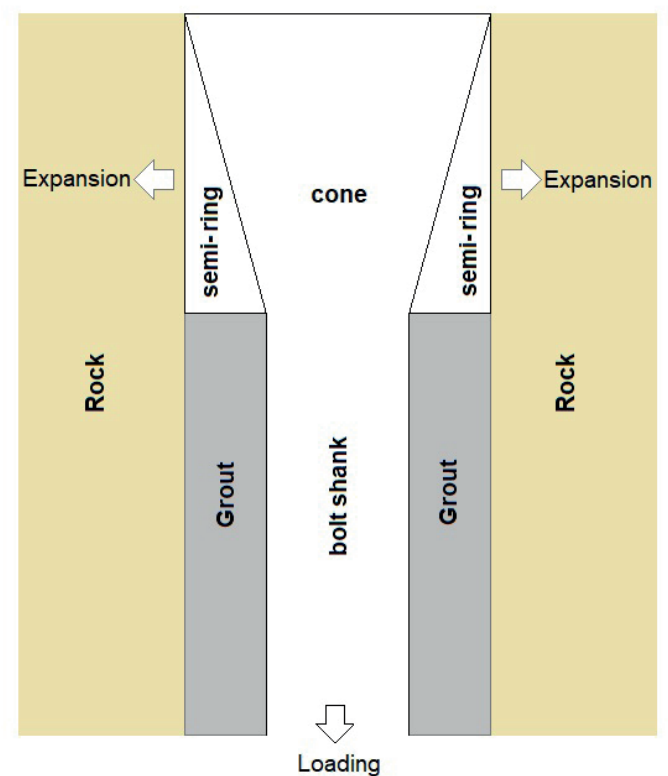

Fig. 1 A shown of anchorage mechanism of the head expansion

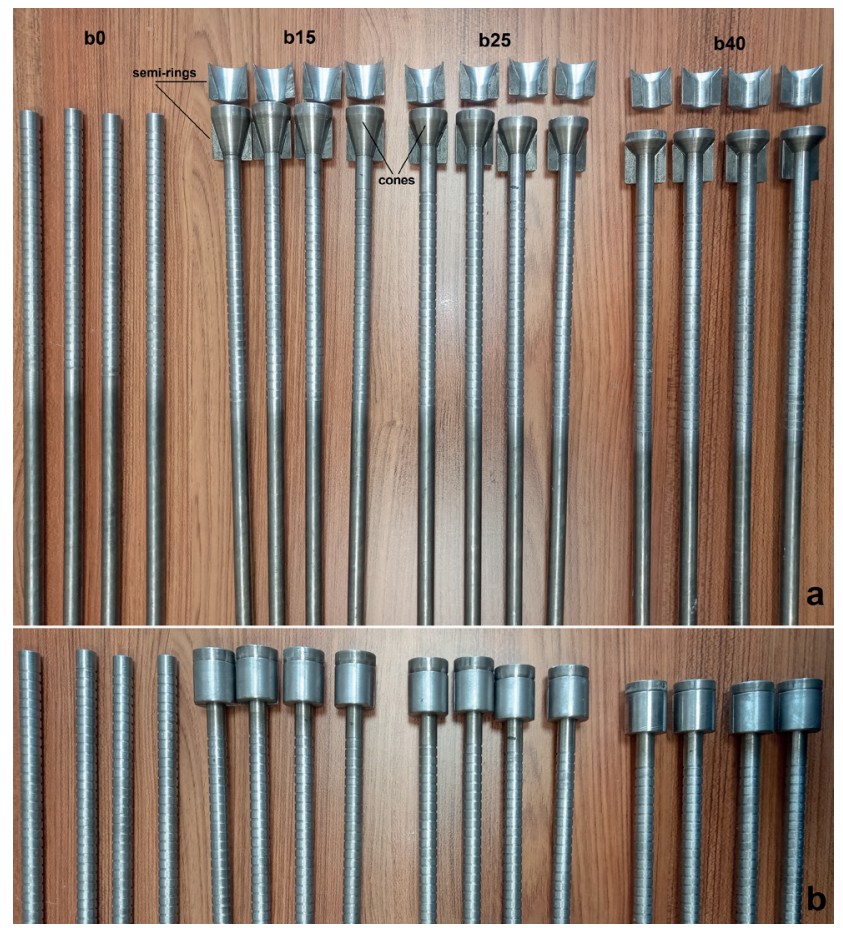

Fig. 2 a) Different head designs, b) semi-rings encircled cone heads (b0: bolts without a conic head, b15: bolts with the cone angle of $15^{\circ}, \mathrm{b} 25$ : bolts with the cone angle of $25^{\circ}$, b40: bolts with the cone angle of $40^{\circ}$ )

The new bolts with auxetic heads were investigated to assess whether both a better failure load and higher energy absorption capacities than those of the ordinary grouted bolts can be supplied, or not. For this aim, a series of displacement controlled, load tests were performed as details given in the following title.

\section{Experimental study}

Within this experimental study, andesite type rock blocks with $250 \mathrm{~mm} \times 150 \mathrm{~mm} \times 120 \mathrm{~mm}$ sizes were drilled by using a stand driller machine and a bit with a diameter of $24 \mathrm{~mm}$ (Fig. 3). Because of the abrasion during the drilling process, diameters of holes varied about $25 \mathrm{~mm}$. Length of drill holes was $200 \mathrm{~mm}$. Four different type rock bolts including three auxetic designs and an ordinary ribbed rebar design without a conic head part were used in the study. Totally, 16 specimens with the shank diameter of $10 \mathrm{~mm}$ were tested in the experimental study (Fig. 4). Various cone part angles of $15^{\circ}, 25^{\circ}$ and $40^{\circ}$ were used to investigate different cut angles effect on load bearing capacity and load-displacement behavior of the bolts. Outside diameter and length of semi-rings of the head part was both $22 \mathrm{~mm}$. Therefore, a thin cement grout layer was filled between the head and hole surfaces. All of the bolt specimens with and without auxetic heads had $200 \mathrm{~mm}$ long parts with same rib design. Therefore, it can be noted that effect of various auxetic heads on the support performances of the ribbed rebars were comparatively investigated in this study.

A cement and water mix was used as the grout material for the bolts. The mix with water to cement ratio of 0.45 by weight was homogenized for 8 minutes by a mixer. The cement grout was poured into the holes after inserting rock bolts. Bolt inserted holes were fully filled with the grout materials. Bolts were gently rotated in the holes to make a well contact to the cement grout mix. Additionally,

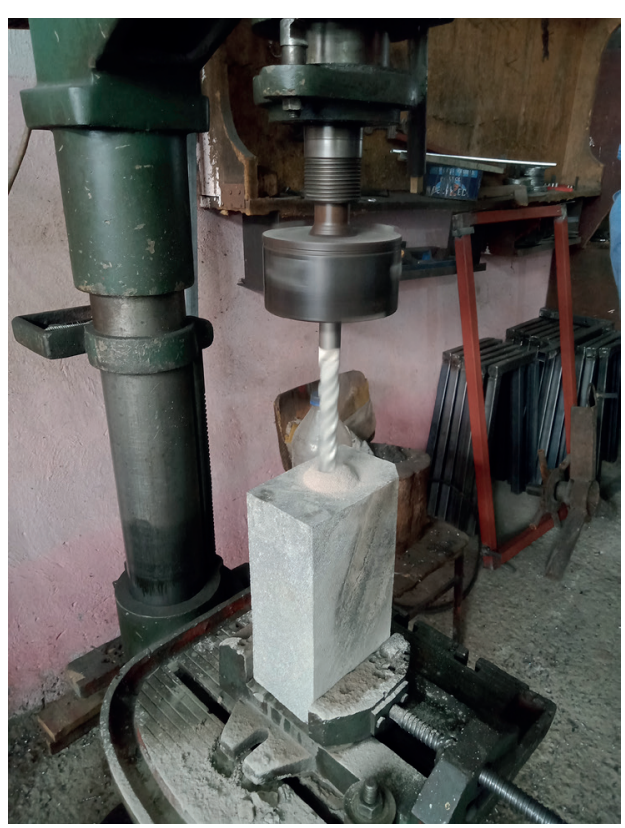

Fig. 3 Drilling hole into rock blocks 


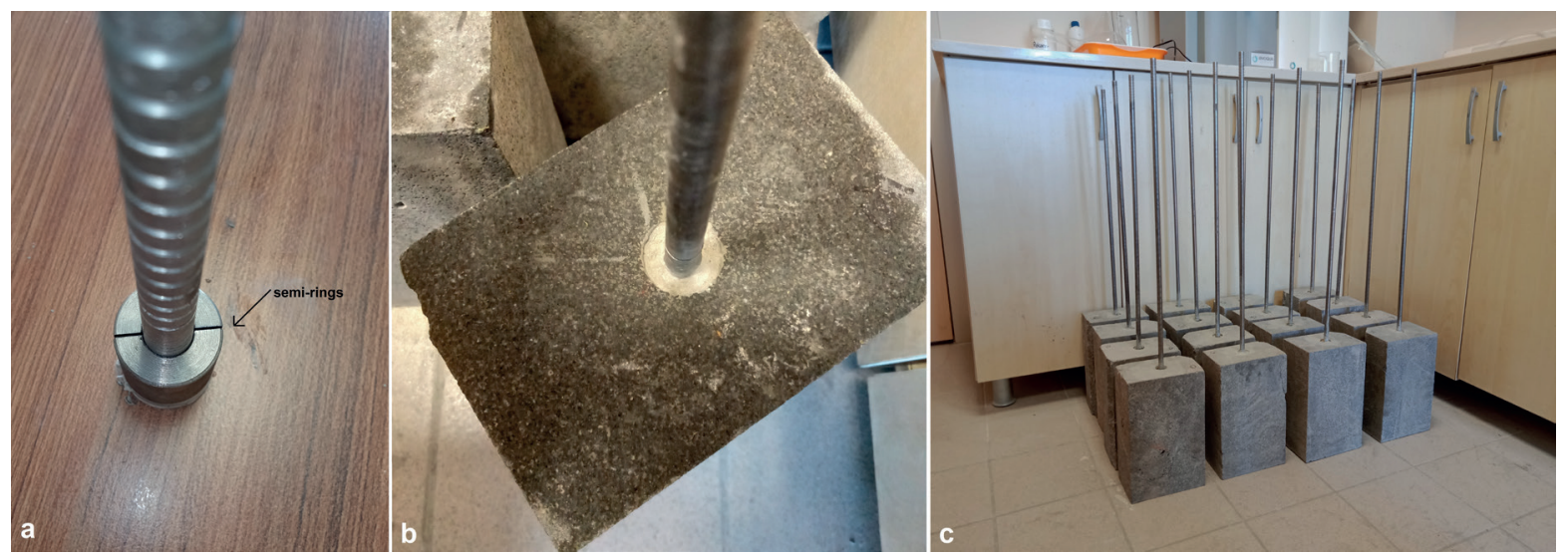

Fig. 4 a) An auxetic bolt before insertion, b and c) grouted bolts in rock blocks

a short vibration process was applied to all grouted rock blocks to make compaction. For standing bolts vertical in the grout mixes, they were passed through drilled plastic plates taped on the blocks. Bolt specimens were carefully checked to be aligned vertically.

After a week of curing time period, grouted bolts in rock blocks were tested using a tension test equipment. The bolted specimens were turned down, inserted through the hole at the up side of the test equipment and the rock blocks were placed on the frame. The deformation-controlled pull-out (adherence) test was carried out holding the bolts by down-side moving grips of the tension test equipment to load in vertical, with a rate chosen to be $0.5 \mathrm{~mm} / \mathrm{min}$ (Fig. 5). The maximum load bearing capacities and loaddisplacement graphs were obtained from the test.

According to the results obtained from this study, bolts with auxetic heads have significantly higher load bearing capacities in comparison with those without the cone parts (Table 1). Because the cone parts were joined to the bolt shanks by the welding method, the failure loads of the auxetic bolts were similar. On the other hand, the stiffness property of the support reactions were found to vary for various head designs. The displacement level at the maximum load bearing capacity was determined to decrease with an increase in the cone angle. It should be reminded

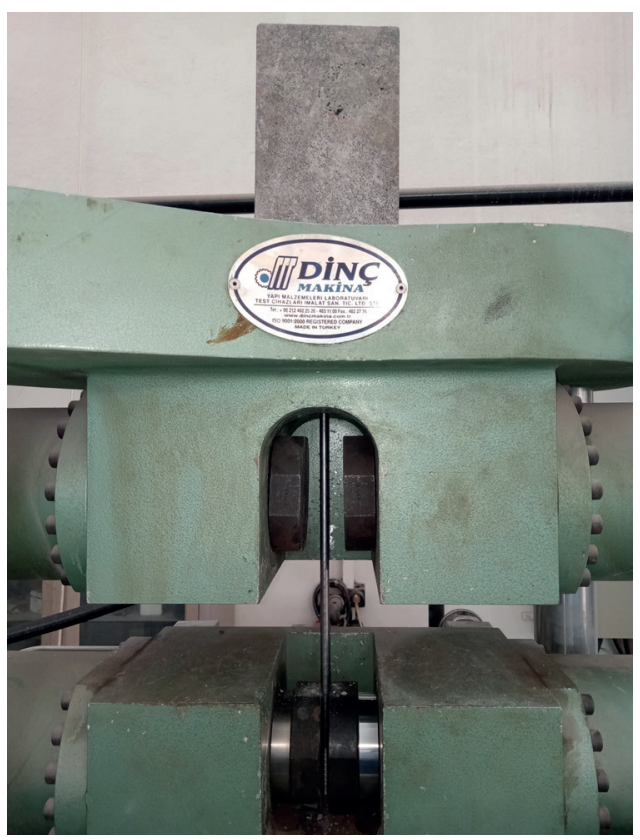

Fig. 5 Pull-out test of the bolts grouted in rock blocks

herein that the maximum cone part angle tested in this study was $40^{\circ}$. The mean displacement data is given for various load levels in Table 2. Because of the early failure and the absence of ploughing while having high displacement levels, the stiffness of the bolts without the cone head part was calculated higher than those of the others.

Table 1 Load bearing capacities obtained from the experimental study (b0: bolts without a conic head, b15: bolts with the cone angle of $15^{\circ}$, b25: bolts with the cone angle of $25^{\circ}$, b40: bolts with the cone angle of $40^{\circ}, S N$ : specimen number, $S D$ : standard deviation, $\Delta_{\text {fmax }}$ : displacement at the maximum

load level, $K_{\text {fmax }}$ : stiffness for the maximum load level, $K_{0.5 \text { max }}$ : stiffness for half of the maximum load level)

\begin{tabular}{|c|c|c|c|c|c|c|c|c|c|}
\hline $\begin{array}{l}\text { Bolt } \\
\text { type }\end{array}$ & $S N$ & $\begin{array}{l}F_{\max } \\
(\mathrm{kN})\end{array}$ & $\begin{array}{l}S D \text { for } F_{\max } \\
(\mathrm{kN})\end{array}$ & $\begin{array}{l}D_{f \max } \\
(\mathrm{mm})\end{array}$ & $\begin{array}{l}S D \text { for } D_{f \max } \\
(\mathrm{mm})\end{array}$ & $\begin{array}{c}K_{f \max } \\
(\mathrm{kN} / \mathrm{mm})\end{array}$ & $\begin{array}{c}S D \text { for } K_{f \max } \\
(\mathrm{kN} / \mathrm{mm})\end{array}$ & $\begin{array}{c}K_{0.5 f \max } \\
(\mathrm{kN} / \mathrm{mm})\end{array}$ & $\begin{array}{l}S D \text { for } K_{0.5 f \max } \\
\quad(\mathrm{kN} / \mathrm{mm})\end{array}$ \\
\hline b0 & 4 & 11.02 & 1.00 & 0.99 & 0.07 & 11.13 & 0.60 & 15.13 & 3.06 \\
\hline b15 & 4 & 35.63 & 0.84 & 6.05 & 0.48 & 5.89 & 0.56 & 7.20 & 2.09 \\
\hline b25 & 4 & 35.68 & 0.51 & 4.73 & 0.39 & 7.54 & 0.68 & 10.15 & 1.22 \\
\hline b40 & 4 & 35.07 & 0.54 & 3.70 & 0.15 & 9.48 & 0.19 & 11.24 & 0.47 \\
\hline
\end{tabular}


Table 2 Experimental displacement data for varying load levels $\left(\Delta_{10 \mathrm{~N} N}\right.$ : displacement at the load level of $10 \mathrm{kN}, \Delta_{20 \mathrm{kN}}$ : displacement at the load level of $20 \mathrm{kN}, \Delta_{30 \mathrm{kN}}$ : displacement at the load level of $30 \mathrm{kN}$ )

\begin{tabular}{lccccccc}
\hline Bolt type & $\mathrm{SN}$ & $\Delta_{10 \mathrm{kN}}(\mathrm{mm})$ & $\mathrm{SD}$ for $\Delta_{10 \mathrm{kN}}(\mathrm{mm})$ & $\Delta_{20 \mathrm{kN}}(\mathrm{mm})$ & $\mathrm{SD}$ for $\Delta_{20 \mathrm{kN}}(\mathrm{mm})$ & $\Delta_{30 \mathrm{NN}}(\mathrm{mm})$ & $\mathrm{SD}$ for $\Delta_{30 \mathrm{kN}}(\mathrm{mm})$ \\
\hline b0 & 3 & 0.66 & 0.16 & NA & - & NA & - \\
15 & 4 & 1.32 & 0.48 & 3.02 & 0.79 & 4.68 & 0.52 \\
25 & 4 & 0.70 & 0.18 & 2.06 & 0.25 & 3.20 & 0.31 \\
40 & 4 & 0.46 & 0.05 & 2.05 & 0.06 & 3.15 & 0.11 \\
\hline
\end{tabular}
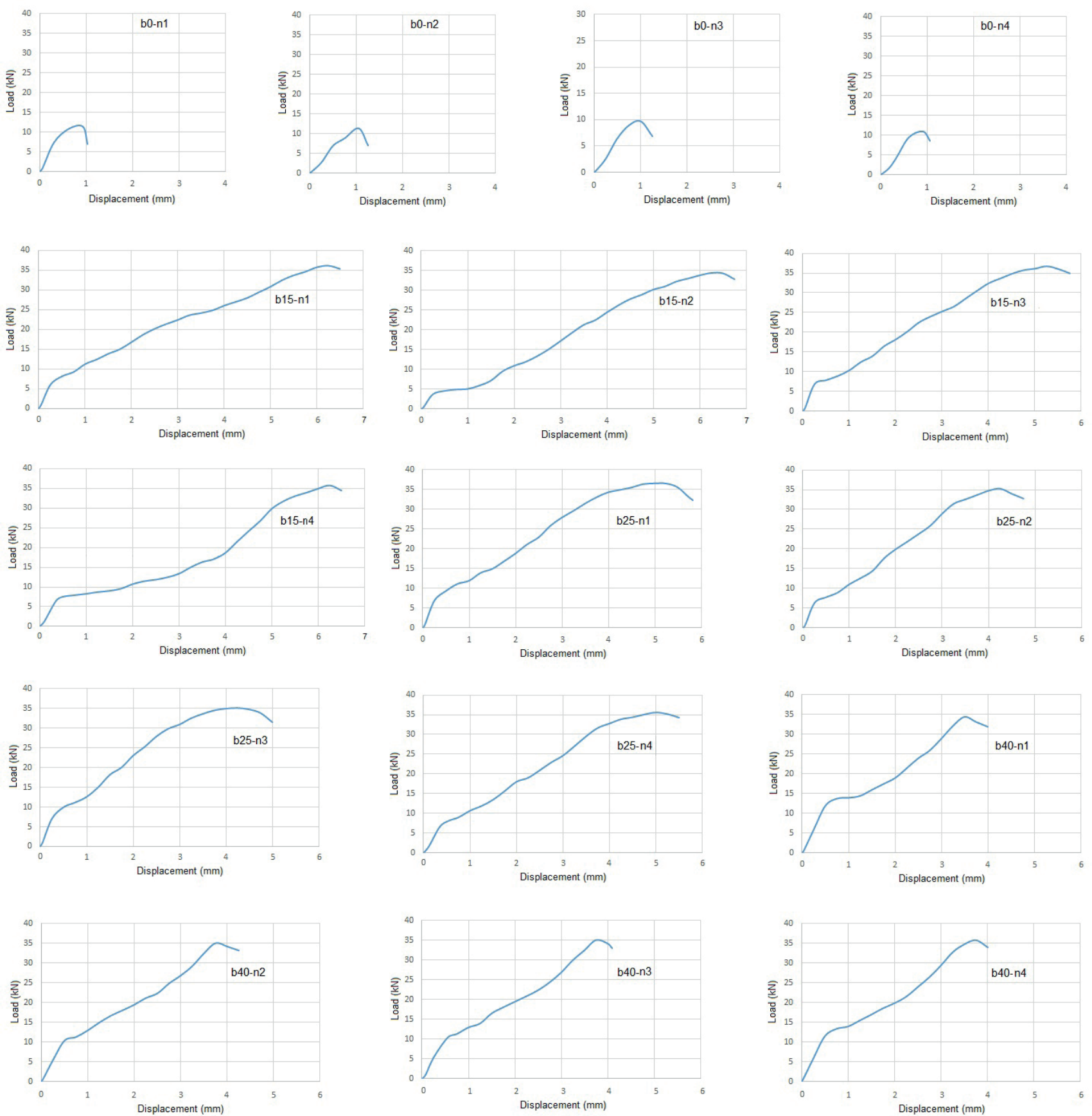

Fig. 6 Load displacement graphs obtained from the experimental study ( $n$ : specimen no) 
Table 3 Energy absorption capacities (EAC) according to the load displacement graphs obtained from the experimental study (J: N.m)

\begin{tabular}{lccc}
\hline Bolt type & SN & EAC $(J)$ & SD for EAC $(J)$ \\
\hline b0 & 4 & 7.15 & 0.81 \\
15 & 4 & 128.13 & 10.21 \\
25 & 4 & 120.94 & 13.20 \\
40 & 4 & 85.95 & 2.88 \\
\hline
\end{tabular}

The auxetic heads were found to significantly improve the energy absorption capacities of the rock bolt samples according to the load displacement graphs (Fig. 6). Energy absorption capacity data calculated in accordance with the area (N.m) under the load displacement graphs is given in Table 3 . In terms of having high energy absorption capacity, the bolt heads with the cone part angle of $15^{\circ}$ were assessed to be better than the other designs. All the bolts with auxetic heads were failed from the welding points (Fig. 7)

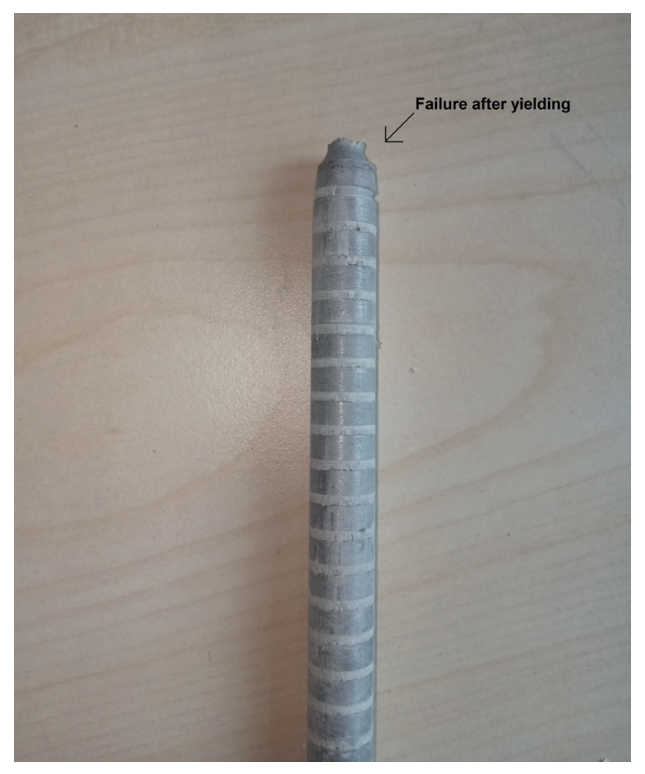

Fig. 7 Failure of auxetic head

bo

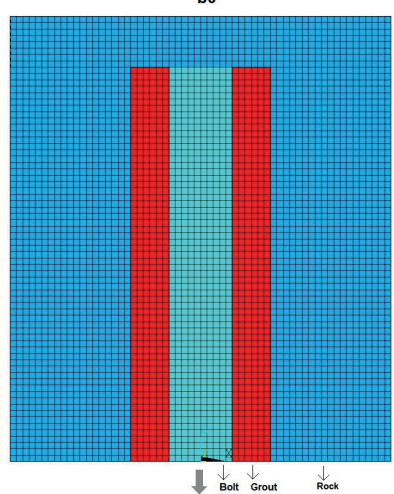

b15

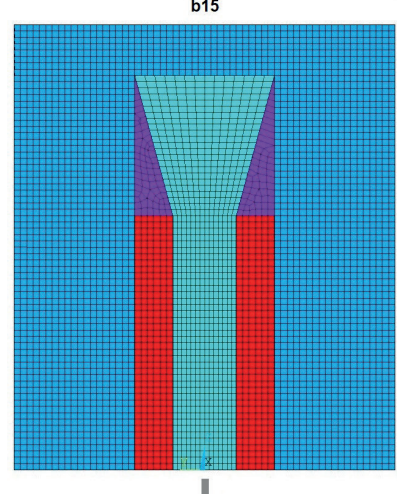

b25

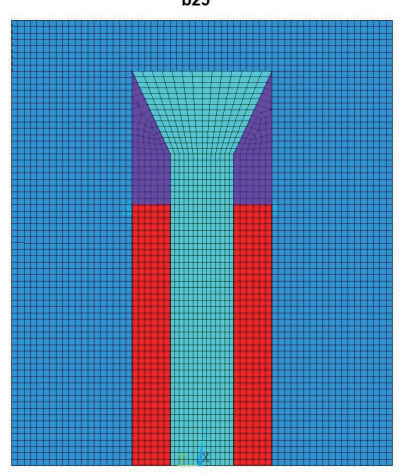

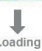

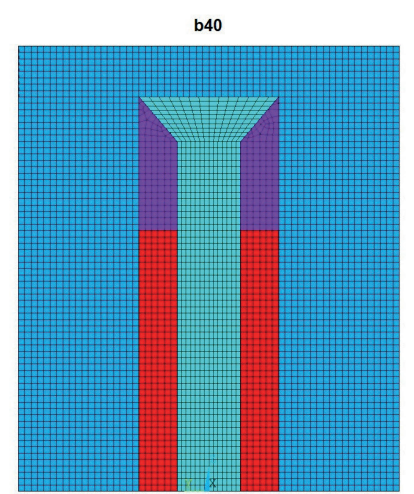

$\Downarrow$

\section{Numerical study}

Finite element analyses of the rock bolts tested in the experimental study (b0, b15, b25, b40) were conducted to investigate their load bearing capacities and support mechanisms. As same with the experimental study, bolt shanks were modelled to have the diameter of $10 \mathrm{~mm}$ and fully grouted in the holes of the rock blocks. The outside of the rings of head part of the auxetic bolts were fully contacted to the drill holes with the diameter of $24 \mathrm{~mm}$. As shown in Fig. 8, the pull-out test was simulated by axial loading in the direction of the bolt shanks. Load was applied from the bolt end being outside of the drill hole. The mesh size in the models was chosen to be $1 \mathrm{~mm}$ (Fig. 8). Various finite element models with different meshes were analyzed in an effort to ensure that the selected meshes are dense enough to provide sufficient solution convergence.

Eight-node solid brick elements, Solid65, were used for the three-dimensional modelling of rock and cement grout, which have the capability of cracking in tension, crushing in compression. Rock and cement grout materials were modelled by considering the linear and non-linear properties defining the behaviors of the elements. Conc model was used to simulate failure in rock materials. Failure surface was defined using uniaxial tensile strength and uniaxial crushing strength values. In the analyses, uniaxial tensile and crushing strengths of rock materials were taken as $10 \mathrm{MPa}$ and $80 \mathrm{MPa}$, respectively. Additionally, shear transfer coefficients for open and closed cracks were considered as $\beta t=0.3$ and $\beta c=0.7$ for the nonlinear solution. Solid185 combined with multilinear kinematic hardening model, Mkin, was used for the three-dimensional modelling of the cone and ring parts. The bolt steel material models were defined as linear elastic until the yielding stress is reached. The yielded steel material was modelled

Fig. 8 Meshes of bolted rock block models 
to plastically deform under constant load level. Standard contact surfaces between cone-ring and ring-rock were simulated with Conta174 and Targe170 contact pair. On the other hand, adhesion between the contact surface of bolt steel and cement grout were modelled with combining the cohesive zone material (CZM) with bonded contact option. In the numerical models, the sliding started as the adhesion between bolt steel and cement grout is achieved. The material properties for rock, cement grout material, bolt steel and contact interfaces are given in Table 4.

For the displacement-controlled loading, loads were divided into multiple sub-steps until the total displacement value of $6 \mathrm{~mm}$. A static analysis was performed for each of the models, and the full Newton-Raphson method was used for non-linear analyses. To investigate the effect of frictions between steel cones and rings, different and typical coefficient of friction values were used in the analyses. Also, different coefficients were analyzed to investigate whether friction forces at the steel and rock contact have a notable change in the results, or not (Table 5). Because the coefficient of friction values are not definite in

Table 4 Material Properties in numerical analyses (SCC: Steel to cement grout contact, CRC: Cement grout to rock contact)

\begin{tabular}{lccccc}
\hline Parameter & Rock & Cement rout & Bolt Steel & SCC & CRC \\
\hline UCS $(\mathrm{MPa})$ & 80 & 35 & 450 & 45 & 50 \\
UTS $(\mathrm{MPa})$ & 10 & 5 & 400 & 4 & 5 \\
E $(\mathrm{GPa})$ & 40 & 15 & 200 & - & - \\
$v$ & 0.27 & 0.30 & 0.25 & - & - \\
Adhesion $(\mathrm{MPa})$ & - & - & - & 4 & 5 \\
\hline
\end{tabular}

Table 5 Coefficient of friction (FC) values in different models

\begin{tabular}{lcc}
\hline Model name & $\begin{array}{c}\text { FC for the steel to rock } \\
\text { contact }\end{array}$ & $\begin{array}{c}\text { FC for the steel to steel } \\
\text { contact }\end{array}$ \\
\hline r0.2-s0.15 & 0.2 & 0.15 \\
r0.4-s0.15 & 0.4 & 0.15 \\
r0.2-s0.35 & 0.2 & 0.35 \\
r0.4-s0.35 & 0.4 & 0.35 \\
\hline
\end{tabular}

the experimental study, use of different coefficients were thought beneficial for comparison of the results and detecting changes if available. Stress distributions and failure mechanisms were plotted for the numerical models.

All the models with the auxetic heads failed from the joining part of the shank and the cone heads as in the experimental observations. Some examples for stress distributions in bolts are given in Fig. 9. The maximum load levels of the numerical models are given in Table 6. According to the results obtained from the numerical study, stiffness values were found to increase with increasing cone angles in parallel with the experimental results. As an important finding for verification of the increase in the stiffness values, the expansion loads applying on the drill hole from the steel rings were found to increase with an increase in the cone angle. Some figures for showing variations of stress distributions in the rock blocks for different cone angles are given in Fig. 10. The maximum stresses in the rock models, which are given in Table 7 were induced near the ring contacts.

Table 6 Load bearing capacity, displacement and stiffness data obtained from the numerical study (no steel to rock and steel to steel contacts for b0 type bolts)

\begin{tabular}{lcccc}
\hline Bolt type & $F_{\max }(\mathrm{kN})$ & $\begin{array}{c}\Delta_{\text {fmax }} \\
(\mathrm{mm})\end{array}$ & $\begin{array}{c}K_{f \max } \\
(\mathrm{kN} / \mathrm{mm})\end{array}$ & $\begin{array}{c}K_{0.5 \max } \\
(\mathrm{kN} / \mathrm{mm})\end{array}$ \\
\hline b0 & 8.54 & 0.28 & 30.50 & 34.17 \\
b15-r0.2-s0.15 & 33.71 & 1.69 & 19.95 & 24.63 \\
b15-r0.4-s0.15 & 34.52 & 1.64 & 21.05 & 24.91 \\
b15-r0.2-s0.35 & 35.14 & 1.70 & 20.67 & 25.10 \\
b15-r0.4-s0.35 & 35.53 & 1.65 & 21.53 & 25.27 \\
b25-r0.2-s0.15 & 33.87 & 1.59 & 21.30 & 24.89 \\
b25-r0.4-s0.15 & 34.02 & 1.42 & 23.96 & 27.56 \\
b25-r0.2-s0.35 & 35.25 & 1.61 & 21.90 & 25.37 \\
b25-r0.4-s0.35 & 34.63 & 1.43 & 24.26 & 28.04 \\
b40-r0.2-s0.15 & 33.16 & 1.38 & 24.02 & 26.65 \\
b40-r0.4-s0.15 & 33.40 & 1.32 & 25.30 & 27.83 \\
b40-r0.2-s0.35 & 33.29 & 1.36 & 24.48 & 27.22 \\
b40-r0.4-s0.35 & 33.56 & 1.31 & 25.71 & 28.98 \\
\hline
\end{tabular}
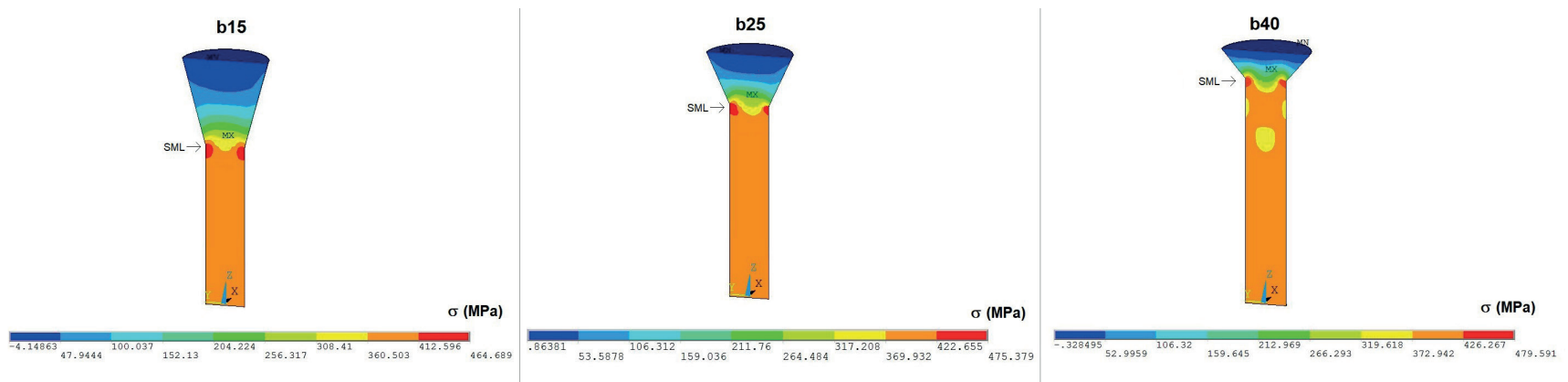

Fig. 9 Stress distributions in rock bolts with different cone angles (r0.2- s0.15) 


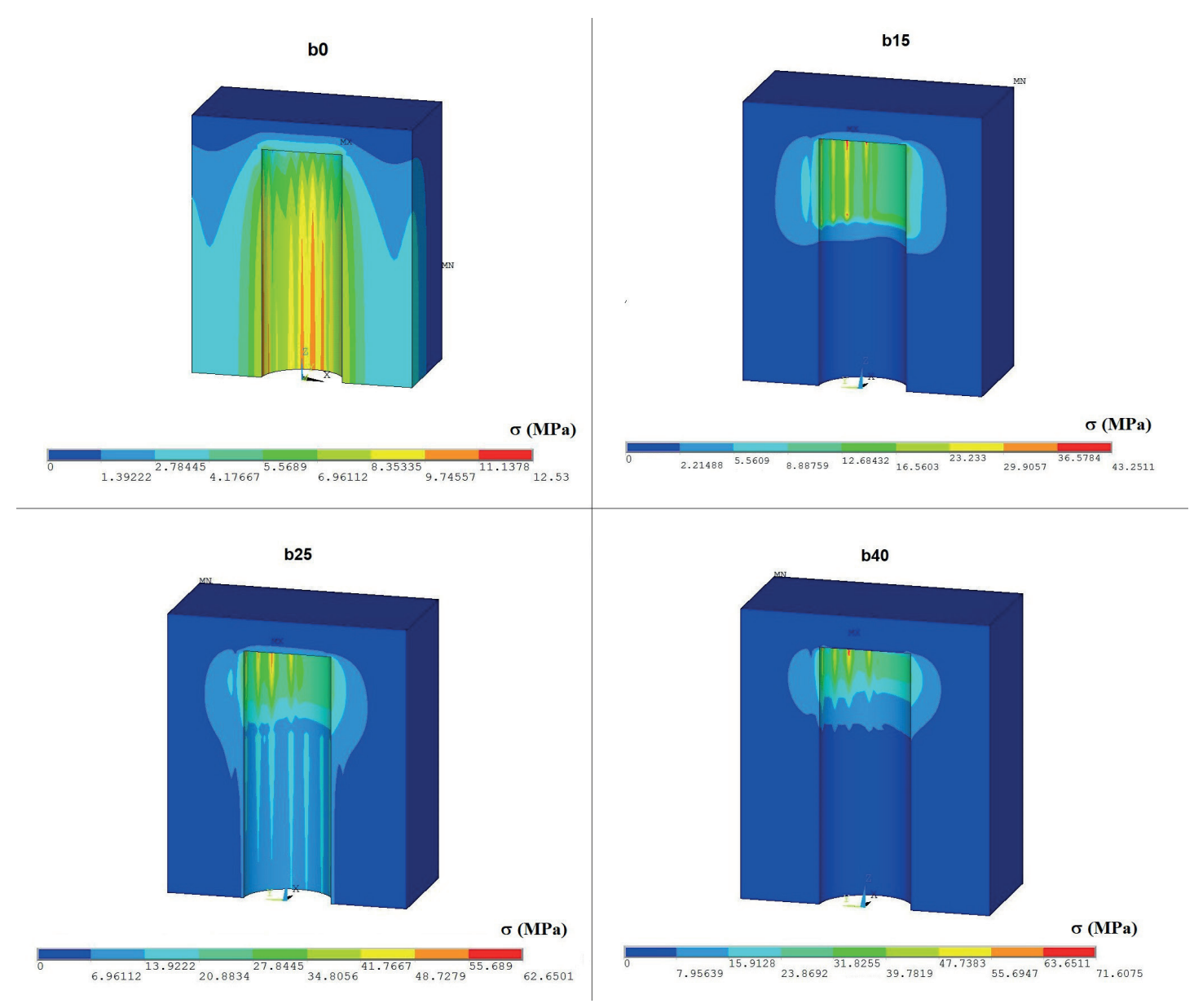

Fig. 10 Stress distributions in rock blocks (r0.2-s0.15)

Table 7 Maximum Von Mises Stress (MVMS) and Maximum principal stress (MPS) values for the ring contact parts of the rock models

\begin{tabular}{lccccc}
\hline $\begin{array}{l}\text { Bolt } \\
\text { type }\end{array}$ & MN & $\begin{array}{c}\text { MVMS } \\
\text { (MPa) }\end{array}$ & $\begin{array}{c}\text { SD for MVMS } \\
(\mathrm{MPa})\end{array}$ & $\begin{array}{c}\text { MPS } \\
(\mathrm{MPa})\end{array}$ & $\begin{array}{c}\text { SD for MPS } \\
(\mathrm{MPa})\end{array}$ \\
\hline b0 & 1 & 12.53 & - & 8.15 & - \\
b15 & 4 & 44.14 & 4.26 & 30.28 & 2.10 \\
b25 & 4 & 63.87 & 4.92 & 43.23 & 2.47 \\
b40 & 4 & 73.06 & 4.71 & 48.69 & 2.25 \\
\hline
\end{tabular}

As same with the experimental study, energy absorption capacities of the auxetic bolt models were notably higher than those of the bolts without the cone heads. The energy absorption capacity values calculated from load-displacement graphs of the numerical models are given in Table 8 . It is confirmed by the numerical analyses that the use of auxetic heads are significantly advantageous for improving the support performances of the grouted rock bolts. The auxetic heads are able to remarkably improve both load bearing and energy absorption capacities of the rock bolts. An example from the numerical results to reflect big differences between support performances of auxetic and other classical bolts (b0) can be seen in Fig. 11.
Table 8 Energy absorption capacity (EAC) values for numerical models (Model numbers)

\begin{tabular}{lccc}
\hline Bolt type & MN & EAC (J) & SD for EAC (J) \\
\hline b0 & 1 & 27 & - \\
b15 & 4 & 180 & 11 \\
b25 & 4 & 165 & 13 \\
b40 & 4 & 147 & 10 \\
\hline
\end{tabular}

The friction coefficient parameters for rock to steel and steel to steel contact surfaces were assessed to be not effective for the variations in the maximum load bearing capacities of the bolts, because the failure load level majorly depends on the steel part strength. On the other hand, load-displacement relations were found to slightly vary with a little effect of the friction coefficients on the stiffness values. As seen from the Table 6, displacement values for a level of an externally applied load to the bolt shank decrease, as a result of an increase in the coefficient of friction values. As it can be well-estimated situation, the coefficient of friction and deformability parameters are inversely proportional that decreases in the steel to steel and steel to rock contact frictions let more displacement at 

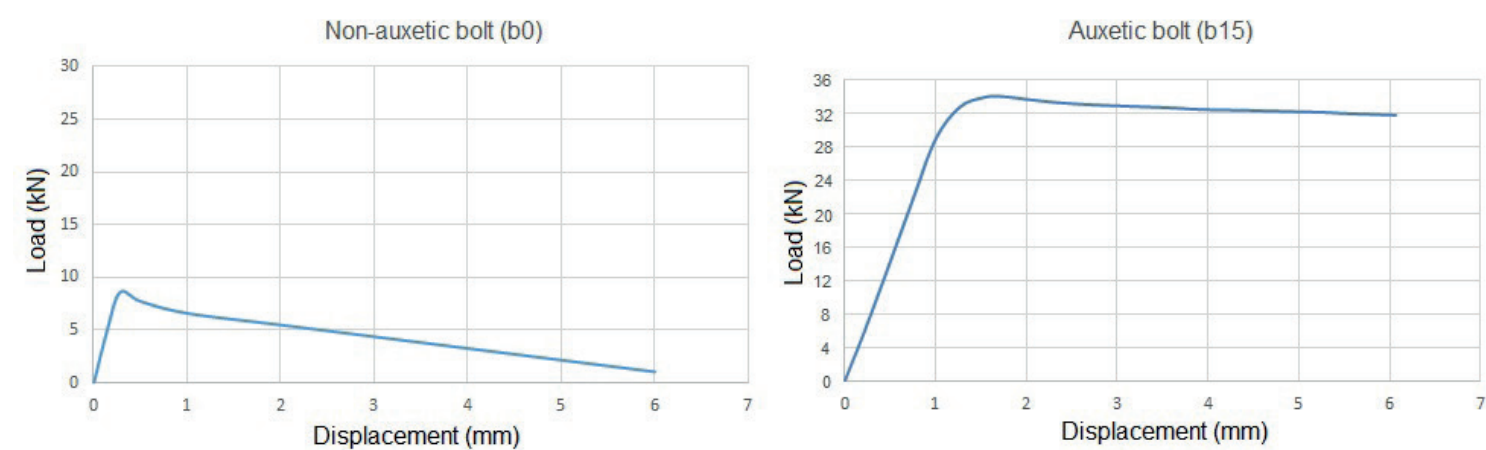

Fig. 11 An example of improvement in support performances of the bolts by using the auxetic heads (models: b0 and b15-r0.4-s0.15)
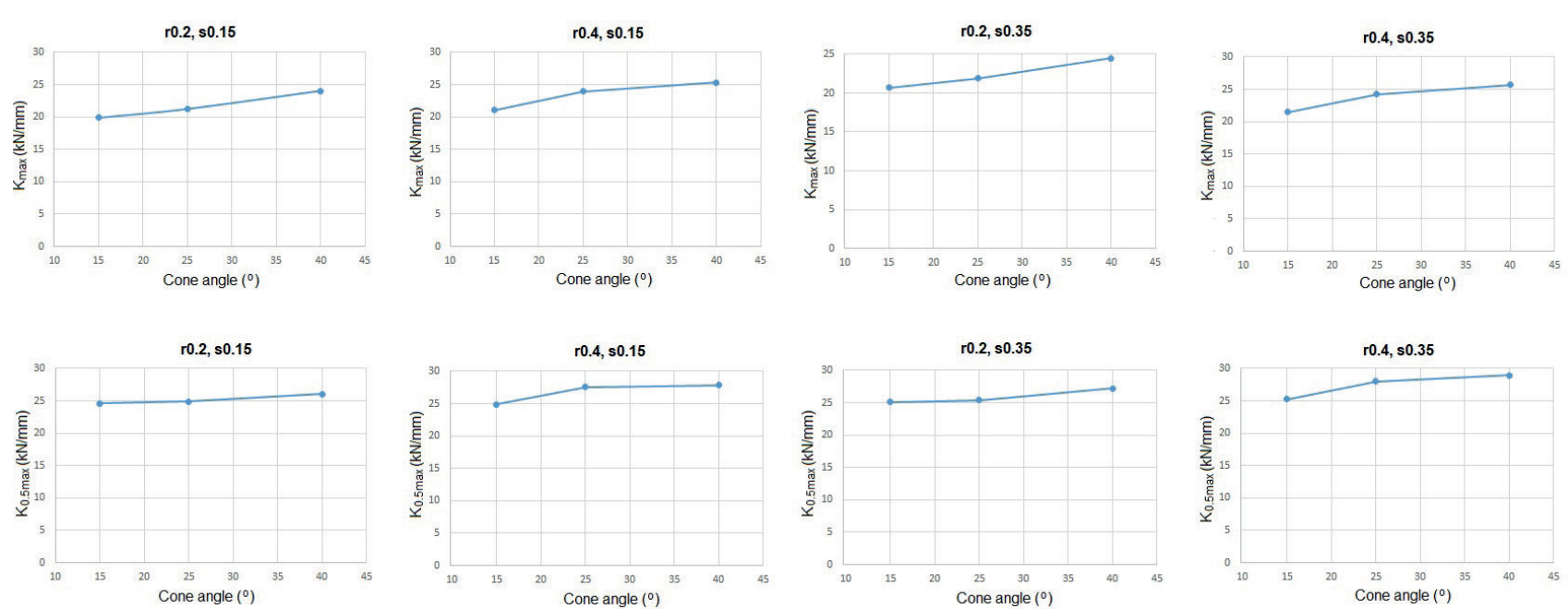

Fig. 12 Variations of stiffness values with the change of cone angle $\left(K_{f \max }\right.$ : Stiffness for the maximum load level, $K_{0.5 f \max }:$ Stiffness for half of the maximum load level)

the friction surfaces. However, the coefficient of friction effect was determined to not cause for a big change in the load displacement behaviors. Rather than the coefficient of friction parameter, the cone part angle was found to have more notable effect on the displacement data (Fig. 12).

\section{Discussions and conclusions}

It was evaluated from the results of this study that new bolt designs have significantly higher load bearing and energy absorption capacities than those of the widely used grouted bolts without a cone head. The high load bearing capacities supplied by auxetic heads are notable for both static and dynamic load conditions.

Significant amounts of increase in the energy absorption capacity make the use of auxetic bolts advantageous for various aims such as combatting the rock burst [15-18]. Low displacement limits and early loose of load bearing capacities can be considered as major problems of ordinary grouted rock bolts with brittle support reactions [19-21]. Use of the new auxetic heads was assessed to increase the ductility in the support reactions. Because very notable load levels can be maintained under high displacement values, deformability characteristics of the grouted bolts with auxetic heads also make their usage advantageous in rock masses with squeezing and/or swelling problems [22-24].

As the most remarkable property of the auxetic bolts, the semi-rings make better anchorage and improve the load bearing capacity due to the expansion towards the drill-hole surface. As the shank is loaded, more anchorage pressure can be supplied by the expansion of the head part consisting of the cone and semi-rings. The cone angles varying between $15^{\circ}$ and $40^{\circ}$ were investigated within this study and found to have a notable effect on the support reactions of the bolts. For a relatively stiff support reaction, high cone angles should be chosen according to both experimental and numerical results. On the other hand, decreasing in cone angles was determined to supply better energy absorption capacities due to the reach of steel failure loads at higher displacement levels. Within different cone angles investigated in this study, $15^{\circ}$ was assessed to be the best choice in terms of having a high energy absorption capacity level. 
Rock mass strength is one of the main parameters for support performances of the rock bolts [25-27]. As a disadvantage of the new bolts, the pressure supplied by the expansion of the head has a possibility to cause cracking in the rock surfaces of holes. Although the rock cracking was not observed in this study carried out by using of high strength rock material specimens and models, the head expansion pressure values were found to be enough to make failure in weak rock materials. Therefore, the auxetic heads can be assessed as non-usable for weak rock masses. As it is obtained from the numerical analyses, an increase in the cone angle makes higher head expansion pressure. The contact pressure was evaluated to reach quite high levels in case of using the high cone angle of $40^{\circ}$.

The increase in the head expansion pressure confirms high stiffness values resulting from increasing in the cone angle. In terms of the cone angle effect and advantages

\section{References}

[1] Kovári, K. "History of the sprayed concrete lining method-part I: milestones up to the 1960s", Tunnelling and Underground Space Technology, 18(1), pp. 57-69, 2003. https://doi.org/10.1016/S0886-7798(03)00005-1

[2] Kovári, K. "History of the sprayed concrete lining method-part II: milestones up to the 1960s", Tunnelling and Underground Space Technology, 18(1), pp. 71-83, 2003.

https://doi.org/10.1016/S0886-7798(03)00006-3

[3] Kömürlü, E., Kesimal, A. "Rock Bolting from Past to Present in 20 Inventions", MT Bilimsel Journal of Underground Resources, 5(9), pp. 69-85, 2016. [online] Available at: https://dergipark.org.tr/tr/ $\mathrm{pub} / \mathrm{mtb} /$ issue $/ 32055 / 354908$

[4] Karakuş, M., Fowell, R. J. "An insight into the New Austrian Tunnelling Method (NATM)", presented at: The 7th Regional Rock Mechanics Symposium, Sivas, Turkey, Oct. 21-22, 2004.

[5] Tonon, F. "Sequential excavation, NATM and ADECO: What they have in common and how they differ", Tunnelling and Underground Space Technology, 25(3), pp. 245-265, 2010. https://doi.org/10.1016/j.tust.2009.12.004

[6] Komurlu, E., Kesimal, A. "Tunnelling and Support Materials from Past to Present", Scientific Mining Journal, 52, pp. 33-47, 2013. (In Turkish)

[7] Li, C. C. "Principles of rockbolting design", Journal of Rock Mechanics and Geotechnical Engineering, 9(3), pp. 396-414, 2017. https://doi.org/10.1016/j.jrmge.2017.04.002

[8] Li, C. C., Stjern, G., Myrvang, A. "A review on the performance of conventional and energy-absorbing rockbolts", Journal of Rock Mechanics and Geotechnical Engineering, 6(4), pp. 315-327, 2014. https://doi.org/10.1016/j.jrmge.2013.12.008

[9] Ranjbarnia, M., Fahimifar, A., Oreste, P. "Practical Method for the Design of Pretensioned Fully Grouted Rockbolts in Tunnels", International Journal of Geomechanics, 16(1), Article number: $04015012,2016$.

https://doi.org/10.1061/(ASCE)GM.1943-5622.0000464 supplied by the use of auxetic heads, experimental and numerical study results are parallel to each other. The new auxetic head designs were found to notably improve the support performances of grouted rock bolts.

In short, the auxetic bolts can be used in grouted rock bolt applications and are strong candidates to be popular in rock engineering. In addition to the increase in the maximum load bearing capacity, use of auxetic heads is significantly beneficial to improve the energy absorption capacities of the grouted rock bolts. This study is a preliminary one on using the auxetic heads with cone and ring parts to improve support performances in the grouted rock bolt applications. According to the results obtained from this study, increase in number of the auxetic bolt applications has a good potential to gain high rate by new investigations on its systematic use and better understanding its support properties.

[10] St-Pierre, L., Hassani, F. P., Radziszewski, P. H., Ouellet, J. "Development of a dynamic model for a cone bolt", International Journal of Rock Mechanics and Mining Sciences, 46(1), pp. 107114, 2009.

https://doi.org/10.1016/j.ijrmms.2008.05.005

[11] Komurlu, E., Kesimal, A. "Experimental Study on Usability of Friction Rockbolts with Plastic Body", International Journal of Geomechanics, 17(9), Article number: 04017058, 2017. https://doi.org/10.1061/(ASCE)GM.1943-5622.0000960

[12] Aksoy, C. O., Ogul, K., Topal, I., Ozer, S. C., Ozacar, V., Posluk, E. "Numerical modeling of non-deformable support in swelling and squeezing rock", International Journal of Rock Mechanics and Mining Sciences, 52, pp. 61-70, 2012. https://doi.org/10.1016/j.ijrmms.2012.02.008

[13] Aksoy, C. O., Uyar, G. G., Posluk, E., Topal, I., Kucuk, K. "Nondeformable support system application at tunnel-34 of AnkaraIstanbul high speed railway project", Structural Engineering and Mechanics, 58(5), pp. 869-886, 2016. https://oi.org/10.12989/sem.2016.58.5.869

[14] Soleiman Dehkordi, M., Shahriar, K., Moarefvand, P., Gharouninik, M. "Application of the strain energy to estimate the rock load in squeezing ground condition of Eamzade Hashem tunnel in Iran", Arabian Journal of Geosciences, 6, pp. 1241-1248, 2013.

https://doi.org/10.1007/s12517-011-0417-1

[15] Stacey, T. R. "Addressing the Consequences of Dynamic Rock Failure in Underground Excavations", Rock Mechanics and Rock Engineering, 49, pp. 4091-4101, 2016. https://doi.org/10.1007/s00603-016-0922-3

[16] Kabwe, E., Wang, Y. "Review on Rockburst Theory and Types of Rock Support in Rockburst Prone Mines", Open Journal of Safety Science and Technology, 5(4), pp. 104-121, 2015. https://doi.org/10.4236/ojsst.2015.54013 
[17] Komurlu, E., Kesimal, A., Okay Aksoy, C. "Use of Polyamide-6 type Engineering Polymer as Grouted Rock Bolt Material", International Journal of Geosynthetics and Ground Engineering, 3, Article number: 37, 2017.

https://doi.org/10.1007/s40891-017-0114-6

[18] Liu, H., Yu, B., Liu, J., Wang, T. "Investigation of impact rock burst induced by energy released from hard rock fractures", Arabian Journal of Geosciences, 12, Article number: 381, 2019. https://doi.org/10.1007/s12517-019-4536-4

[19] Li., C. C. "A Practical Problem with Threaded Rebar Bolts in Reinforcing Largely Deformed Rock Mass", Rock Mechanics and Rock Engineering, 40(5), pp. 519-524, 2007. https://doi.org/10.1007/s00603-006-0094-7

[20] Yang, S.-Q., Chen, M., Jing, H.-W., Chen, K.-F., Meng, B. "A case study on large deformation failure mechanism of deep soft rock roadway in Xin'An coal mine, China", Engineering Geology, 217, pp. 89-101, 2017.

https://doi.org/10.1016/j.enggeo.2016.12.012

[21] Yokota, Y., Zhao, Z., Nie, W., Date, K., Iwano, K., Koizumi, Y., Okada, Y. "Development of a new deformation-controlled rock bolt: Numerical modelling and laboratory verification", Tunnelling and Underground Space Technology, 98, Article number: 103305, 2020. https://doi.org/10.1016/j.tust.2020.103305

[22] Uyar, G. G., Aksoy, C. O. "New Support Suggestions to High Swelling Clayey Rock Mass", Journal of Mining Science, 54, pp. 617-627, 2018 https://oi.org/10.1134/S1062739118044087
[23] Barla, G. "Full-face excavation of large tunnels in difficult conditions", Journal of Rock Mechanics and Geotechnical Engineering, 8(3), pp. 294-303, 2016.

https://doi.org/10.1016/j.jrmge.2015.12.003

[24] Barla, G., Barla, M., Bonini, M., Debernardi, D. "Guidelines for TBM tunnelling in squeezing conditions - a case study", Géotechnique Letters, 4(2), pp. 83-87, 2014. https://doi.org/10.1680/geolett.13.00065

[25] Aghchai, M. H., Maarefvand, P., Salari Rad, H. "Analytically Determining Bond Shear Strength of Fully Grouted Rock Bolt Based on Pullout Test Results", Periodica Polytechnica Civil Engineering, 64(1), pp. 212-222, 2020 https://doi.org/10.3311/PPci.15195

[26] Komurlu, E., Demir, S. "Length Effect on Load Bearing Capacities of Friction Rock Bolts", Periodica Polytechnica Civil Engineering, 63(3), pp. 718-725, 2019. https://doi.org/10.3311/PPci.14081

[27] Komurlu, E., Demir, S. "Use of Rock Mass Rating (RMR) values for Support Designs of Tunnels excavated in Soft Rocks without Squeezing Problem", Geoscience Engineering, 65(2), pp. 1-17, 2019.

http://doi.org/10.35180/gse-2019-0007 